\title{
Seasonal variation in the composition and melting behavior of milk fat
}

\author{
M. K. Larsen, ${ }^{1}$ K. K. Andersen, ${ }^{2}$ N. Kaufmann, ${ }^{3}$ and L. Wiking \\ Department of Food Science, Aarhus University, AU Foulum, Blichers Alle 20, DK-8830 Tjele, Denmark
}

\begin{abstract}
Dairy bulk tank milk was sampled during 1 yr from 2 conventional (C1 and $\mathrm{C} 2$ ) and 1 organic dairy (O1) for studying the seasonal variation as well as the variation between dairies in the composition and properties of milk fat. The composition of fatty acids (FA) as well as triglycerides (TAG) in milk fat was analyzed, and the melting properties of milk fat were analyzed by use of differential scanning calorimetry. The main differences in fat content and composition of FA in milk fat between dairies included a higher fat content, greater proportion of C18:0, and smaller proportion of C16:0 in milk from dairy $\mathrm{C} 2$, which could be associated with a higher frequency of Jersey herds supplying milk to this dairy. The organic milk was characterized by a higher proportion of $\mathrm{C} 18: 3 \mathrm{n}-3, \mathrm{C} 18: 2$ cis-9,trans-11, C6 to C14, a lower proportion of C18:1 cis-9, and a higher melting point of the low-melting fraction. The TAG composition showed a greater proportion of C24 to C38 TAG in milk fat from dairy $\mathrm{O} 1$ and a greater proportion of C52 to C54 TAG in milk fat from dairy $\mathrm{C} 2$, which was in accordance with the differences in FA composition. Melting point of the low-melting fraction was higher for milk fat from dairy O1 compared with dairies $\mathrm{C} 1$ and $\mathrm{C} 2$, whereas no differences between dairies were observed with respect to melting points of the medium- and high-melting fractions. The seasonal variation in FA composition was most pronounced for dairy $\mathrm{O} 1$ although similar patterns were observed for all dairies. During the summer, the content of C18:0 and C18:1 cis-9 in milk fat was greater, whereas the content of C14:0 and C16:0 was lower. In addition, the content of C18:2 cis-9,trans-11 and C18:1 trans-11 increased in late summer for dairy O1. The differential scanning calorimetry thermograms of individual milk fat samples could be divided into 3 groups by principal component analysis. For dairy O1, summer samples belonged to
\end{abstract}

\footnotetext{
Received December 20, 2013.

Accepted April 7, 2014.

${ }^{1}$ Corresponding author: mette.larsen@agrsci.dk

${ }^{2}$ Present address: iNANO, Department of Molecular Biology and Genetics, Aarhus University, Gustav Wieds Vej 14, DK-8000 Aarhus C, Denmark.

${ }^{3}$ Present address: Arla Food Ingredients, Danmark Protein,
} Sønderupvej 26, DK-6920 Nr. Vium, Denmark. group 1, spring and autumn samples to group 2, and winter samples to group 3. For dairy C1 winter samples (group 2), were separated from other samples (group 1 ), and for dairy $\mathrm{C} 2$ all samples were in group 1. Individual melting points were related to FA composition, and the melting point of the low-melting fraction was positively correlated to the content of C14:0 and C16:0 in milk fat and negatively correlated to the content of C18:1 cis-9 and C18:0.

Key words: fatty acid composition, triglyceride composition, melting property

\section{INTRODUCTION}

Fat is a main component in milk and has important nutritional and technological properties. However, the composition of milk fat is not constant, which provides both challenges and opportunities for the dairy industry. About $98 \%$ of milk fat is represented in the form of triglycerides (TAG), which are essentially esters of glycerol and FA. The properties of milk fat are, to a large extent, determined by the FA composition, which can vary significantly. Factors that influence FA composition include feed, stage of lactation, lactation number, breed, health status, and genetics. In milk fat, more than 400 different FA have been identified (Jensen, 2002), which are dominated by SFA ( 70\%), followed by MUFA and small amounts of PUFA. The FA in milk originate from different sources: de novo synthesis in the mammary gland, body fat reserves, FA from feed, and FA produced from bacteria in the rumen (Jensen, 2002).

Softer texture has been reported for dairy products (yogurt, ice cream, and cheese) when manufactured from milk rich in unsaturated fat (Chen et al., 2004; Couvreur et al., 2006; Hurtaud et al., 2010). Historically, it is known that butter produced during summer, when cows are grazing, is softer than butter produced from winter milk. This effect has been correlated to the changes in the FA composition over the season, where the unsaturated-to-saturated FA ratio increases during the summer, which is related to grazing (Toledo et al., 2002; Heck et al., 2009; Larsen et al., 2010). To obtain a more uniform texture of butter throughout the year, manufacturers can give the cream a season-dependent temperature treatment to manipulate fat crystal com- 
position and size, which defines the spreadability of the butter. Effects of changes in FA composition have been extensively studied from a nutritional point of view, whereas the technological properties have received much less attention. Texture of butter and other dairy products may be analyzed by rheological or sensory methods; however, the texture is affected by processing conditions as well as the composition of the raw milk. Differential scanning calorimetry (DSC) studies have been performed to determine the crystallization and melting behavior of isolated milk fat, as these properties determine the physiochemical and sensory properties of dairy products with a great content of fat, and an increased content of unsaturated FA has been shown to decrease melting points and increase proportion of lowmelting TAG (Couvreur et al., 2006; Ortiz-Gonzalez et al., 2007; Smet et al., 2010; Buldo et al., 2013). By use of extruded linseed feeding (60\% of concentrate), Smet et al. (2010) reported a decrease in SFA in milk fat, from 71 to $61 \%$, accompanied by a decrease in melting points of $3.8,1.6$, and $1.7^{\circ} \mathrm{C}$ of the low-, medium-, and high-melting fractions, respectively. In addition, the low-melting TAG increased from 32 to $44 \%$ and the medium- and high-melting TAG decreased. Based on cream samples from individual cows from different farms, Buldo et al. (2013) reported that the melting point of the lowest melting fraction is positively correlated to the concentration of $\mathrm{C} 16: 0$ and negatively correlated to the concentration of $\mathrm{C} 18: 1$ cis-9 in milk fat. Ortiz-Gonzalez et al. (2007) altered the milk FA composition by abomasal infusion of various oils and reported a positive relationship between the concentration of C16:0 in milk fat and the melting point of the high melting fraction, whereas the concentration of C18:2 was negatively correlated to the melting point of the high-melting fraction.

The objective of the current work was to study the effect of season on the FA composition in both Danish conventional and organic milk and how this affects melting properties. Furthermore, the study aimed to relate the FA and TAG composition to the melting point pattern of milk fat by using multivariate data analysis. The main seasonal variation in feeding is generally the use of grazing during summer, which affects milk FA composition. Raw milk was sampled from 3 Danish dairies over a period of 12 mo at least once a month, with higher frequencies during spring and autumn. The milk fat was analyzed for FA composition, as well as TAG composition, and melting behavior of crystallized milk fat was investigated with DSC. The seasonal variations in FA and TAG composition were correlated to variations in the melting behavior. The main hypotheses of the present study were that organic milk fat differed from conventional milk fat in FA composition as well as melting properties, and that the seasonal variation in these parameters was more pronounced for organic milk, as grazing is compulsory in Danish organic farming, whereas grazing is only practiced by a limited number of conventional dairy farmers.

\section{MATERIALS AND METHODS}

\section{Milk Sampling}

Conventional bulk tank milk from 2 Danish dairies (C1 and C2) was collected from January 2010 to December 2010. Furthermore, organic bulk tank milk from 1 Danish dairy (O1) was collected from March 2010 to December 2010. Milk was sampled from raw milk silo tanks with agitation, where the incoming milk is stored until standardization and processing at least once a month, with a higher frequency during spring and autumn. Milk was sampled at the dairies in the morning, transported directly to the laboratory, analyzed for total fat content by use of a Milkoscan FT2 (Foss Electric, Hillerød, Denmark), and divided into subsamples, which were kept at $-20^{\circ} \mathrm{C}$ until analysis.

Samples were grouped according to 6 periods of sampling, defined as January to February (period 1; calendar wk 1-8), March to April (period 3; calendar wk 9-15), May to June (period 5; calendar wk 16-23), July to August (period 7; calendar wk 24-36), September to October (period 9; calendar wk 37-44), and November to December (period 11; calendar wk 45-52). Periods 1, 3, and 11 included winter feeding; period 5 covered early grazing; and periods 7 and 9 covered regrowth and late regrowth of pastures. In organic farming, a compulsory use of grazing exists when climatic conditions allow (European Council, 2007), and the beginning of the grazing period was determined as the third Sunday of April (www.okodag.dk). During winter and under winter-like weather conditions, which is not unusual from November to March, animals cannot be kept outside unless all animals have access to dry bedding (Foedevarestyrelsen, 2011); thus, the grazing period was assumed to end by the end of October. No registration of feed composition was conducted, as milk samples were dairy bulk tank milk samples.

\section{Analysis of FA Composition and TAG Composition}

For analysis of FA composition, milk fat was isolated by centrifugation and subsequently methylated by use of sodium methylate, as described previously, except that heptane was used as solvent instead of pentane (Larsen et al., 2013). Methyl esters were analyzed by gas chromatography and relative amounts of individual FA were calculated by use of external standards 
(Larsen et al., 2013). For each dairy and each period, pooled milk fat samples were prepared for TAG composition according to ISO 17678 (ISO, 2010) by use of an Agilent 7890A gas chromatograph with a flame ionization detector (Agilent Technologies, Santa Clara, CA) equipped with an Rtx-65TG column $(2.5 \mathrm{~m}, 0.25 \mathrm{~mm}$ i.d., 0.10- $\mu \mathrm{m}$ film thickness; Restek, Bellafonte, PA).

\section{Thermal Analysis of Milk Fat}

Pooled milk fat samples were used for thermal analysis, where the melting profile of the milk fat was analyzed by use of DSC (Q 2000, TA Instruments, New Castle, DE). The DSC was calibrated with indium, and nitrogen was used to purge the system. Between 15 and $20 \mathrm{mg}$ of milk fat was loaded in a hermetic aluminum pan. An empty, sealed pan was used as reference. The samples were equilibrated at $65^{\circ} \mathrm{C}$ for 15 min and then cooled to $-40^{\circ} \mathrm{C}$ at $10^{\circ} \mathrm{C} / \mathrm{min}$ and isothermally held for $5 \mathrm{~min}$. Afterward the temperature was increased to $65^{\circ} \mathrm{C}$ at $20^{\circ} \mathrm{C} / \mathrm{min}$. The DSC analyses were performed in triplicate. The melting off-set temperatures of the low-, medium-, and high-melting fractions (LMF, MMF, HMF, respectively) were identified with Universal Analysis software from TA Instruments. Data for heat flow from 0 to $40^{\circ} \mathrm{C}$ were used for multivariate analysis.

\section{Statistical Analysis}

To investigate significant differences $(P<0.05)$ between dairies, one-way ANOVA of univariate data was conducted using SAS version 9.2 for Windows (SAS Institute, Inc., Cary, NC). Multivariate analysis was carried out as principal component analysis (PCA) and partial least squares projection to latent structures (PLS) using Simca P+ version 13.0 (Umetrics AB, Umeaa, Sweden). In multivariate models, variables were centered and scaled to unit variance, except for the PCA of DSC data and the PLS analyses of relationships between melting points and FA and TAG, respectively, which were pareto scaled.

\section{RESULTS AND DISCUSSION}

Milk was sampled from silo tanks at 1 organic dairy, O1, and the 2 conventional dairies, $\mathrm{C} 1$ and $\mathrm{C} 2$. Milk fat content, FA composition, TAG composition, and melting temperatures were analyzed and mean results are given in Table 1 for each dairy.

\section{Variation Between Dairies}

The main differences in fat content and FA composition between dairies (Table 1) included greater fat content in milk, a greater proportion of $\mathrm{C} 18: 0$, and a smaller proportion of C16:0 in milk fat from dairy C2, whereas milk from the organic dairy O1 could be characterized by a higher proportion of C18:3n-3, CLA cis 9,trans-11, C6 to C14, and a lower proportion of C18:1 cis-9 in milk fat. The higher proportion of C18:3n-3 and CLA cis-9,trans-11 is normally observed in comparisons of organic and conventional milk and is due to the higher use of grass products (Butler et al., 2011). The greater proportion of de novo synthesized FA (C6-C14) in organic milk and the corresponding lower content of C18:1 cis-9 could be due to a higher use of fat supplements and rapeseed products at conventional dairy farms (Larsen et al., 2012). The differences between conventional dairies $\mathrm{C} 1$ and $\mathrm{C} 2$ included greater fat content and lower desaturase indices for milk from dairy $\mathrm{C} 2$. These are characteristic differences between milk from Holstein and Jersey cows (Poulsen et al., 2012), and, as dairy C2 is situated in an area where the frequency of Danish Jersey dairy farms is higher, the breed difference is most likely responsible for the difference between conventional dairies.

The main differences in TAG composition between dairies (see Table 1) included higher C24 to C38 in samples from dairy $\mathrm{O} 1$ and higher $\mathrm{C} 52$ to $\mathrm{C} 54$ in samples from dairy $\mathrm{C} 2$, and these differences could be related to higher proportions of $\mathrm{C} 6$ to $\mathrm{C} 14$ and $\mathrm{C} 18 \mathrm{FA}$, respectively. Other studies have also reported positive correlations between $\mathrm{C} 18 \mathrm{FA}$ and C50 to C54 TAG, as well as between $\mathrm{C} 4$ to $\mathrm{C} 14 \mathrm{FA}$ and $\mathrm{C} 32$ to C38 TAG (Shi et al., 2001; Ortiz-Gonzalez et al., 2007).

The melting point of the LMF was higher for dairy O1 compared with the 2 conventional dairies (Table 1 ), whereas no differences in the melting points of the MMF and HMF were observed. Milk fat from dairy O1 was also characterized by a higher content of C32 to C40 TAG, which belong to the LMF. The apparent discrepancy between a higher amount of liquid-like TAG and a higher melting point of the LMF could be due to a larger LMF peak, which may shift the melting point. Calculation of enthalpy from the DSC thermograms could give relative amounts of the individual fractions. However, due to the shape of the curve, the calculation of the enthalpy of the LMF would be subject to high uncertainty. Melting points are normally related to FA composition, especially the degree of saturation. Thus, melting points of all 3 fractions of milk fat were lowered after linseed feeding, which increases the amount of unsaturated FA in milk fat (Smet et al., 2010). Others, however, have only measured melting point of the HMF and have reported decreases in this parameter with increasing amounts of unsaturated FA (Shi et al., 2001; Ortiz-Gonzalez et al., 2007). Increased amounts of grazing has increased the content of unsaturated 
Table 1. Mean \pm SD of fat, FA composition, triglyceride composition, and melting points of milk samples from 1 organic and 2 conventional Danish dairies

\begin{tabular}{|c|c|c|c|c|}
\hline Item & $\begin{array}{l}\text { Organic } \\
\text { dairy } 1\end{array}$ & $\begin{array}{l}\text { Conventional } \\
\text { dairy } 1\end{array}$ & $\begin{array}{l}\text { Conventional } \\
\text { dairy } 2\end{array}$ & $P$-value \\
\hline Number of samples & 18 & 20 & 19 & \\
\hline Fat content $(\mathrm{g} / \mathrm{kg}$ of milk) & $43.6 \pm 1.8$ & $43.9 \pm 2.8$ & $46.7 \pm 2.6$ & 0.001 \\
\hline \multicolumn{5}{|l|}{$\mathrm{FA}(\mathrm{g} / \mathrm{kg}$ of $\mathrm{FA})$} \\
\hline $\mathrm{C} 6$ to $\mathrm{C} 12$ & $126 \pm 5.8$ & $121 \pm 4.4$ & $124 \pm 5.8$ & 0.01 \\
\hline C11 to $\mathrm{C} 17$ & $25 \pm 1.3$ & $22 \pm 1.1$ & $23 \pm 1.0$ & $<0.001$ \\
\hline C14:0 & $119 \pm 4.7$ & $113 \pm 2.9$ & $111 \pm 2.5$ & $<0.001$ \\
\hline C14:1 & $10.7 \pm 0.9$ & $10.2 \pm 0.4$ & $9.4 \pm 0.4$ & $<0.001$ \\
\hline C16:0 & $306 \pm 19.6$ & $305 \pm 6.2$ & $288 \pm 10.0$ & $<0.001$ \\
\hline C16:1 & $18 \pm 0.8$ & $19 \pm 1.0$ & $17 \pm 1.0$ & $<0.001$ \\
\hline C18:0 & $115 \pm 8.3$ & $115 \pm 4.4$ & $129 \pm 5.1$ & $<0.001$ \\
\hline C18:1 trans -11 & $17 \pm 4.1$ & $16 \pm 1.1$ & $19 \pm 1.6$ & 0.003 \\
\hline C18:1 cis-9 & $205 \pm 15.2$ & $225 \pm 7.0$ & $224 \pm 7.2$ & $<0.001$ \\
\hline C18:2n-6 & $18 \pm 2.3$ & $20 \pm 0.6$ & $21 \pm 1.2$ & $<0.001$ \\
\hline C18:3n-3 & $10.2 \pm 1.3$ & $5.5 \pm 0.3$ & $4.7 \pm 0.3$ & $<0.001$ \\
\hline CLA cis-9,trans-11 & $6.9 \pm 1.7$ & $6.0 \pm 0.3$ & $6.4 \pm 0.4$ & 0.04 \\
\hline C14 desaturase index ${ }^{1}$ & $0.082 \pm 0.0043$ & $0.083 \pm 0.0024$ & $0.078 \pm 0.0021$ & $<0.001$ \\
\hline \multicolumn{5}{|c|}{ Triglycerides ( $\mathrm{g} / \mathrm{kg}$ of triglycerides) } \\
\hline $\mathrm{C} 24$ to $\mathrm{C} 30$ & $30 \pm 1.6$ & $28 \pm 1.7$ & $27 \pm 2.6$ & 0.01 \\
\hline C32 & $26 \pm 2.2$ & $25 \pm 1.3$ & $24 \pm 1.4$ & $<0.001$ \\
\hline C34 & $58 \pm 2.5$ & $54 \pm 2.0$ & $50 \pm 2.7$ & $<0.001$ \\
\hline C36 & $105 \pm 5.8$ & $99 \pm 3.3$ & $91 \pm 5.3$ & $<0.001$ \\
\hline C38 & $120 \pm 3.4$ & $117 \pm 3.6$ & $113 \pm 4.2$ & $<0.001$ \\
\hline $\mathrm{C} 40$ & $93 \pm 3.5$ & $93 \pm 2.1$ & $96 \pm 4.7$ & 0.04 \\
\hline $\mathrm{C} 42$ & $65 \pm 5.8$ & $64 \pm 1.9$ & $66 \pm 4.2$ & NS \\
\hline $\mathrm{C} 44$ & $67 \pm 5.3$ & $65 \pm 2.2$ & $64 \pm 4.2$ & NS \\
\hline $\mathrm{C} 46$ & $75 \pm 5.1$ & $72 \pm 2.1$ & $71 \pm 4.3$ & 0.02 \\
\hline $\mathrm{C} 48$ & $92 \pm 3.4$ & $93 \pm 2.8$ & $88 \pm 3.4$ & $<0.001$ \\
\hline C50 & $116 \pm 5.6$ & $121 \pm 5.9$ & $124 \pm 13.9$ & NS \\
\hline C52 & $111 \pm 12.7$ & $119 \pm 6.7$ & $126 \pm 11.9$ & $<0.001$ \\
\hline C54 & $41 \pm 8.5$ & $49 \pm 4.0$ & $59 \pm 7.2$ & $<0.001$ \\
\hline \multicolumn{5}{|l|}{ Melting points (offset ${ }^{\circ} \mathrm{C}$ ) } \\
\hline Low-melting fraction & $11.9 \pm 0.7$ & $10.8 \pm 0.4$ & $10.6 \pm 0.3$ & $<0.001$ \\
\hline Medium-melting fraction & $20.1 \pm 0.9$ & $20.1 \pm 1.3$ & $19.4 \pm 0.7$ & NS \\
\hline High-melting fraction & $36.3 \pm 0.8$ & $36.4 \pm 0.8$ & $36.1 \pm 0.9$ & NS \\
\hline
\end{tabular}

${ }^{1} \mathrm{C} 14$ desaturase index $=\mathrm{C} 14: 1 /(\mathrm{C} 14: 0+\mathrm{C} 14: 1)$.

FA in milk fat, decreased the solid fat content at temperatures ranging from 8 to $37^{\circ} \mathrm{C}$, but has not affected melting points of the different fractions (Couvreur et al., 2006).

\section{Variation in FA Composition}

For each dairy, the seasonal variation in milk fat composition was investigated, and Figure 1 shows how milk fat content varied in the sampled milk from the 3 dairies in different weeks. The fat percentage was highest in the winter and lowest in the summer. Similar seasonal effects in the fat content are seen in other studies and are primarily reported as related to feed factors, such as grazing in the summer period (Toledo et al., 2002; Heck et al., 2009; Larsen et al., 2010).

Principal component analysis was used to visualize the variation in the FA composition of milk fat between dairies (Figure 2A). Samples from dairy $\mathrm{C} 1$ and $\mathrm{C} 2$ were clustered by dairy, and these 2 clusters were situated close to each other. Samples from dairy O1 were not clustered, and some samples were situated close to samples from the conventional dairies whereas others differed. The loading plot (Figure 2B) showed the characteristic differences were higher contents of C18:3n-3, CLA cis-9,trans-11, and C11 to C17 in milk fat from dairy O1, higher contents of C18:0, C18:1 cis-9, and C18:2n-6 in milk fat from dairy $\mathrm{C} 2$, and higher contents of $\mathrm{C} 16: 0$ and $\mathrm{C} 16: 1$ in milk fat from dairy C1. Samples were labeled by periods (Figure 2A), and the seasonal variation in milk FA composition for dairy $\mathrm{O} 1$ is displayed clearly at the PCA score plot, where samples from period 11 were characterized by highest content of $\mathrm{C} 14$ and $\mathrm{C} 16 \mathrm{FA}$; this content decreased in periods 3 and 5 and the content of C18:0 and C18:1 increased. For samples from periods 7 and 9, the content of CLA cis-9,trans-11 increased, and, for samples from period 9, the content of C14 and C16 FA started increasing at the expense of C18:0 and C18:1 cis-9. Similar, but much less pronounced patterns in the seasonal variation were observed for the 2 conventional dairies, and the main FA responsible for the seasonal variation were C14:0, 


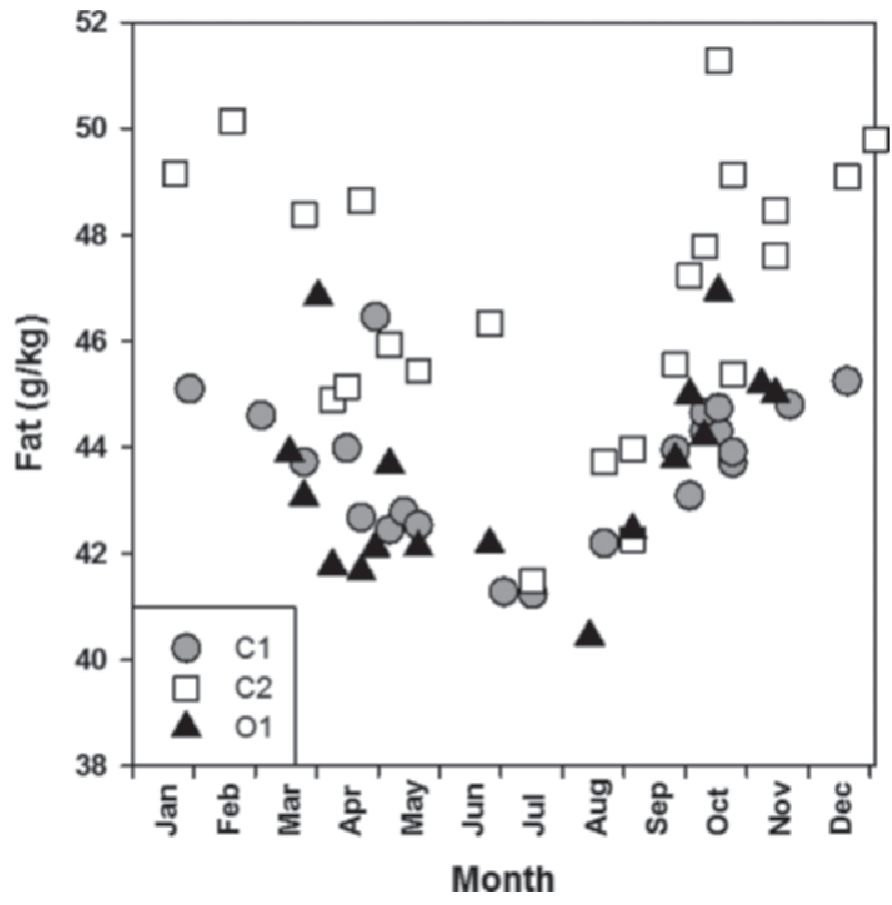

Figure 1. Variation in the fat content in raw milk samples from 2 conventional ( $\mathrm{C} 1$ and $\mathrm{C} 2)$ and 1 organic (O1) dairy during $1 \mathrm{yr}$.

C16:0, C18:1 cis-9, and CLA cis-9,trans-11. In Figure 3, the magnitude of the seasonal variation of $\mathrm{C} 14, \mathrm{C} 16: 0$, C18:1 cis-9, and CLA cis-9,trans-11 is shown. The seasonal variation was most pronounced for dairy $\mathrm{O} 1$, but was still significant for the 2 other dairies. The seasonal variation in $\mathrm{C} 14, \mathrm{C} 16: 0$, and $\mathrm{C} 18: 1$ cis-9 was in accordance with previous studies, where the concentration of SFA was lower and the concentration of unsaturated FA was greater in summer compared with winter (Toledo et al., 2002; Larsen et al., 2010). The large difference in the content of CLA cis-9,trans-11 in milk fat from dairy $\mathrm{O} 1$ is characteristic for organic milk and is due to pasture feeding in summer (Butler et al., 2008).

\section{Variation in TAG Composition}

A PCA of the TAG composition (Figure 4A) showed that samples from dairy $\mathrm{O} 1$ and dairy $\mathrm{C} 2$ could be separated, whereas samples from dairy $\mathrm{C} 1$ could not be separated from any of the others. The grouping is to some extent similar to what was obtained by the PCA of FA composition (Figure 2A), although much less pronounced. The loadings plot of the PCA of TAG composition (Figure 4B) showed that samples from dairy $\mathrm{C} 2$ were associated with greater content of C40, $\mathrm{C} 42$, and $\mathrm{C} 50$ to C54, whereas the samples from dairy O1 were associated with greater content of C24 to C38 and $\mathrm{C} 44$ to C48. For dairy O1, a tendency of a seasonal variation was observed, where the samples from periods 5 and 7 had lower content of $\mathrm{C} 24$ to $\mathrm{C} 38$ and $\mathrm{C} 44$ to $\mathrm{C} 48$ and higher content of C50 to C54 compared with samples from periods 9 and 11 , with samples from period 3 being intermediate (Figure 4A). Similar tendencies could not be observed for the 2 conventional dairies.
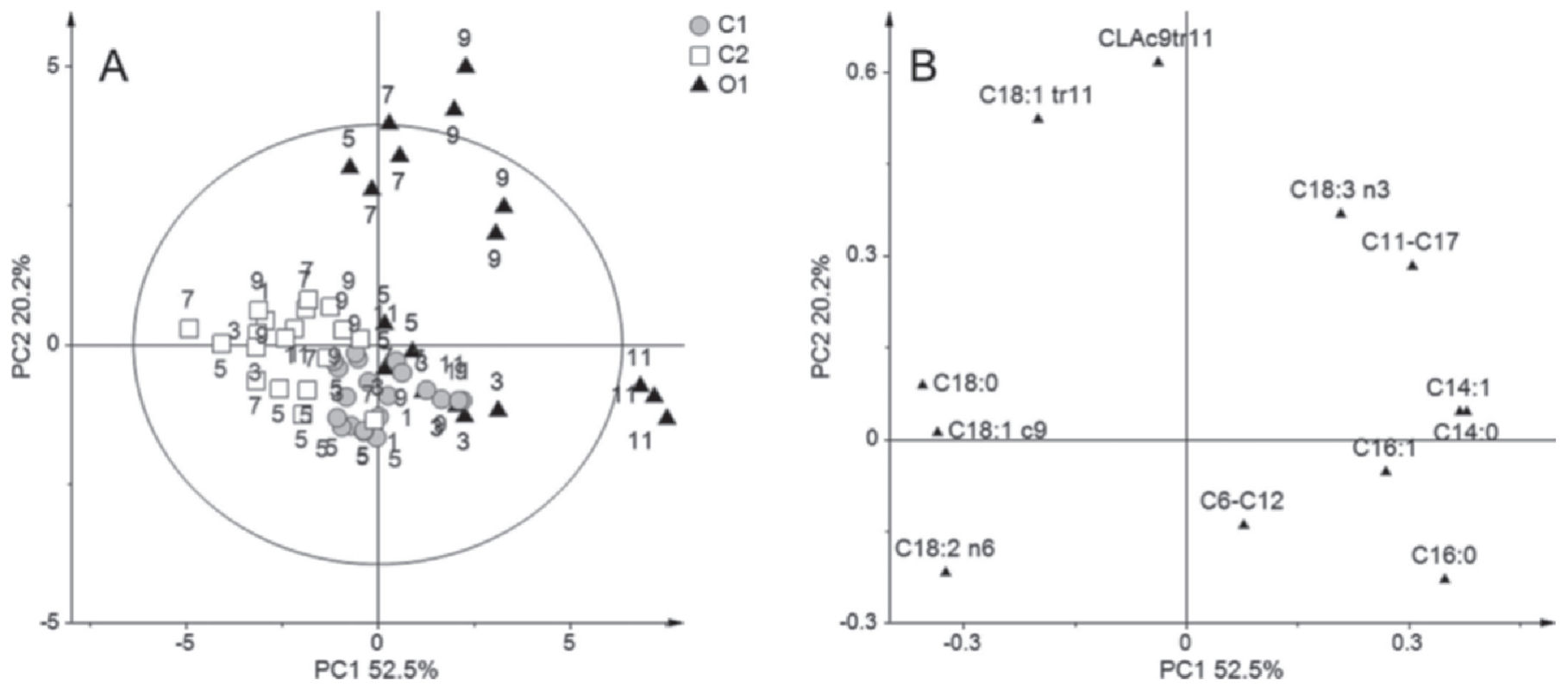

Figure 2. Principal component (PC) analysis of FA composition of raw milk samples from 2 conventional (C1 and C2) and 1 organic (O1) dairy. (A) Plot of scores labeled by period of sampling (1 = January-February; $3=$ March-April; $5=$ May-June; $7=$ July-August; $9=$ September-October; $11=$ November-December). (B) Plot of loadings (FA). $\mathrm{c}=$ cis; $\mathrm{tr}=$ trans. 

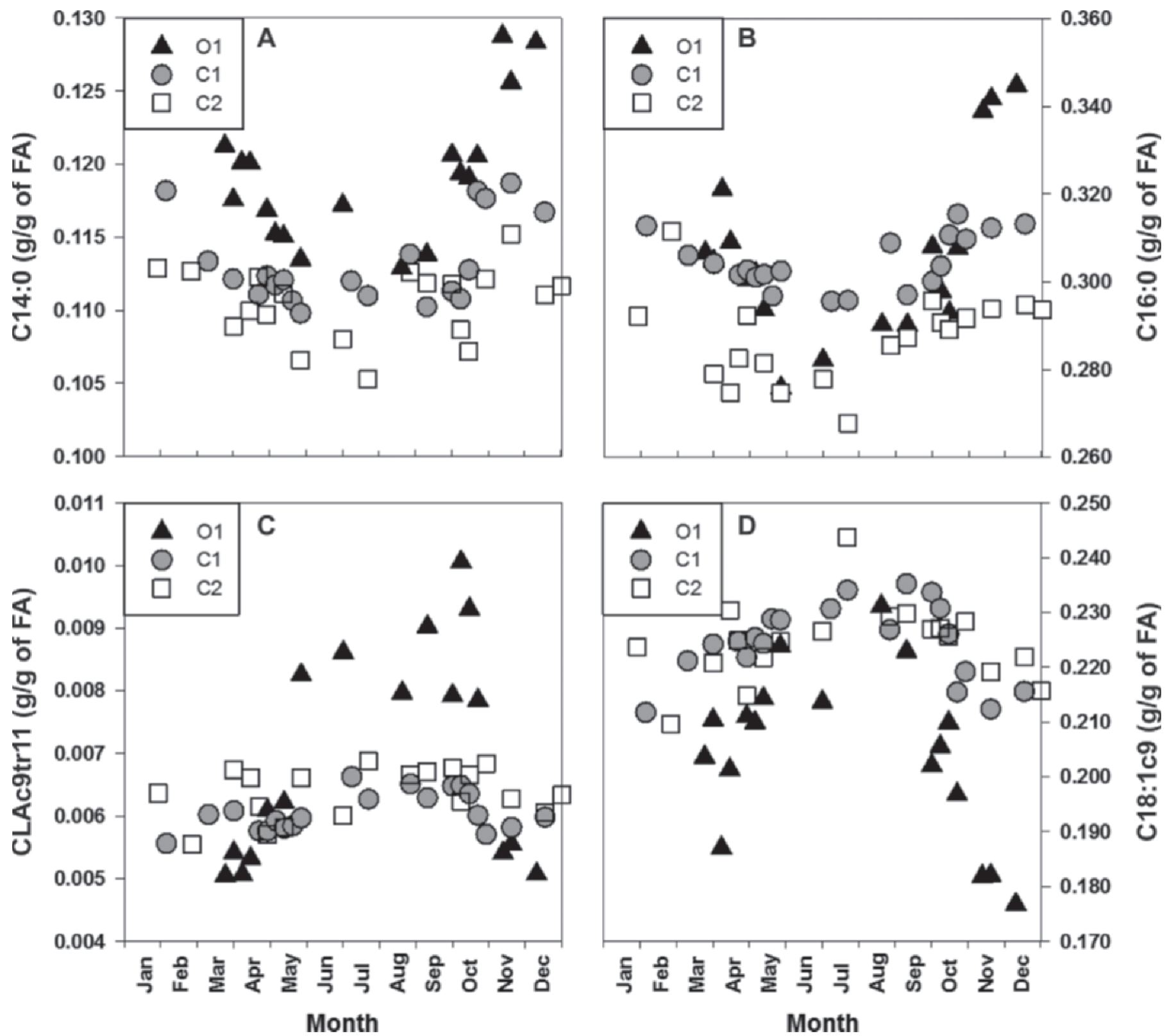

Figure 3. Variation in the FA content in raw milk samples from 2 conventional (C1 and $\mathrm{C} 2$ ) and 1 organic (O1) dairy during 1 yr, with plots for (A) C14:0, (B) C16:0, (C) CLA cis-9,trans-11, and (D) C18:1 cis-9. c = cis; tr = trans.

\section{Relations Between FA and TAG}

A PLS analysis of FA as $\mathrm{X}$ variables and TAG as $\mathrm{Y}$ variables (data not shown) showed that more than $50 \%$ of the variation could be predicted by the model according to cross validation for the TAG C34, C36, C48, C52, and C54. The TAG C34, C36, and C48 were positively related to $\mathrm{C} 14, \mathrm{C} 16: 0$, and $\mathrm{C} 11$ to $\mathrm{C} 17$ FA and negatively related to C18:0, C18:1 cis-9, and C18:2n-6, whereas the TAG C52 and C54 were positively related to $\mathrm{C} 18: 0, \mathrm{C} 18: 1$ cis-9, and $\mathrm{C} 18: 2 \mathrm{n}-6$ and negatively related to $\mathrm{C} 14, \mathrm{C} 16: 0$, and $\mathrm{C} 11$ to $\mathrm{C} 17 \mathrm{FA}$.
These results confirm the assumed relations based on mean values of FA and TAG (as previously mentioned) and are in accordance with previous findings (Shi et al., 2001; Ortiz-Gonzalez et al., 2007).

\section{Variation in Melting Behavior}

The heat flow data of the DSC melting curves from 0 to $40^{\circ} \mathrm{C}$ of the milk fat samples were analyzed by PCA (Figure 5). Analysis revealed clustering into 3 groups, where group I included all samples from dairy C2, samples from periods 5 to 9 from dairy $\mathrm{C} 1$, and samples 

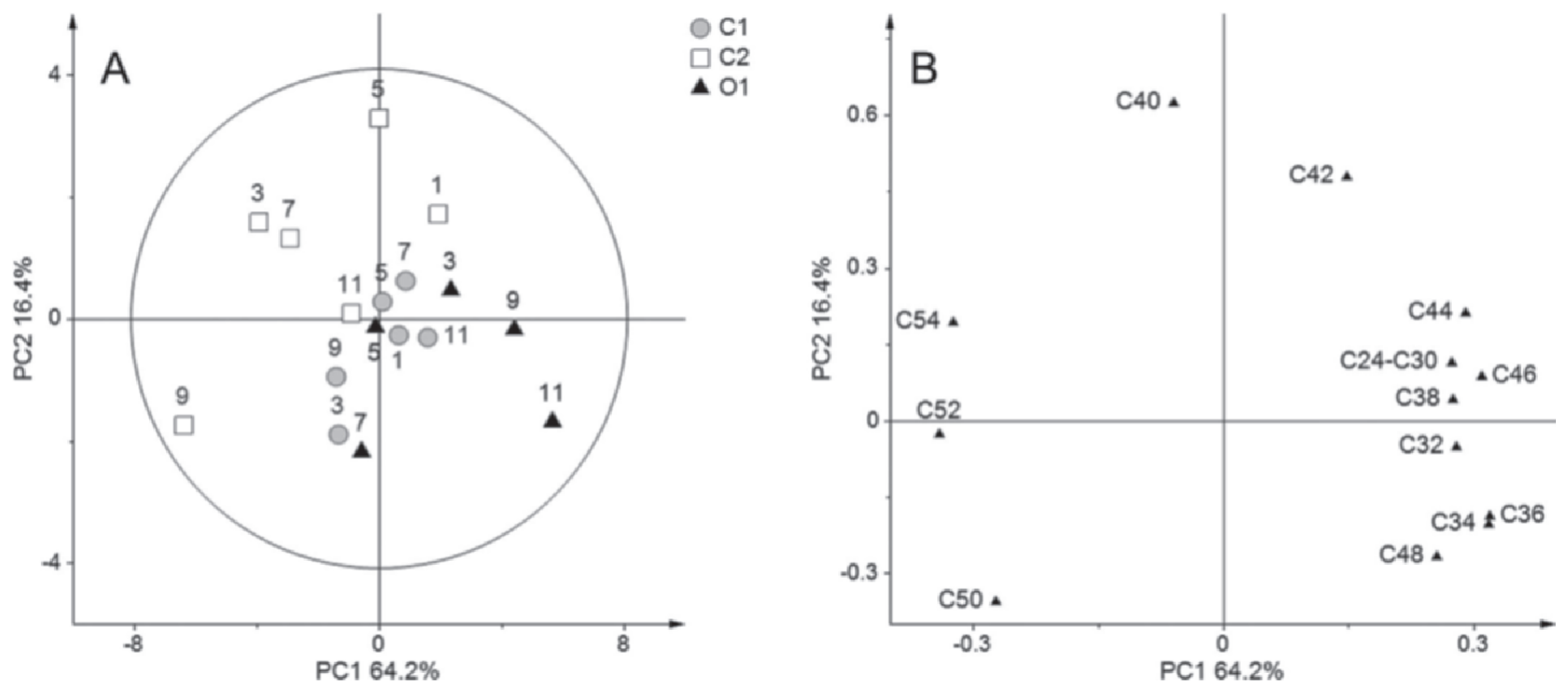

Figure 4. Principal component (PC) analysis of triglyceride composition of raw milk samples from 2 conventional (C1 and C2) and 1 organic (O1) dairy. (A) Plot of scores labeled by period of sampling ( $1=$ January-February; $3=$ March-April; $5=$ May-June; $7=$ July-August; $9=$ September-October; 11 = November-December). (B) Plot of loadings (triglycerides).

from period 7 from dairy O1. Group II included samples from periods 5 and 9 from dairy $\mathrm{O} 1$ and samples from periods 1, 3, and 11 from dairy C1. Group III consisted of samples from periods 3 and 11 from dairy O1. These groupings show highest seasonal variation for the samples from dairy O1, which were grouped into winter samples (group III), summer samples (group I), and spring and autumn samples (group II). For dairy C1, winter samples (group II) were separated from other samples (group I). Minimal seasonal variation was observed for dairy $\mathrm{C} 2$ samples. These differences could be relevant in the butter manufacturing, as winter samples from dairy C2 may be treated as summer samples, whereas winter samples from dairy $\mathrm{C} 1$ should be treated differently. The differences in seasonal variation between dairies in melting behavior resembled the differences in FA composition, where variation was highest for dairy $\mathrm{O} 1$ and lowest for dairy $\mathrm{C} 2$.

Three individual samples from central positions in the groups of the PCA plot (Figure 5A) were selected to investigate which differences in DSC data could characterize the differences between groups. The thermograms of these 3 samples are shown in Figure 5B and the main differences are position of peaks and signal magnitude. The positions of peaks are indicative of melting points, where samples from group I melt at lower temperatures, and samples from group II melt at higher temperatures. These variables are closely related to the score of $\mathrm{PC} 1$, and low-melting points give a high positive score. The magnitude of signal is higher in samples from group III compared with group I and II, especially between 9 and $15^{\circ} \mathrm{C}$, and this difference is related to a higher score of $\mathrm{PC} 2$. The signal magnitude is a measure of how much energy is required to melt a sample, thus a higher fraction of the TAG for samples in group III melts between 9 and $15^{\circ} \mathrm{C}$.

The PCA grouping of samples was much more distinct for DSC data than for FA and TAG, which indicates that melting properties are determined by more factors than just FA and TAG composition. However, if the analysis had included individual TAG, where length and structure of each of the $3 \mathrm{FA}$ was known, another TAG pattern would most likely have been revealed.

\section{Prediction of Melting Temperatures}

Although the entire DSC thermogram is the best expression of the melting properties, melting points calculated from DSC data are valuable information as well, and as melting points depend on TAG and FA composition, attempts were made to predict melting points by use of TAG and FA. A PLS model where TAG were used as $\mathrm{X}$ variables and melting points as $\mathrm{Y}$ variables showed that 40,10 , and $1 \%$ of the variation in LMF, MMF, and HMF, respectively, melting points could be explained, and no more than $20 \%$ of the variation could be predicted based on cross validation. This was considered a poor model and it was concluded that it was not possible to relate the melting points and the TAG composition unless the individual TAG composi- 

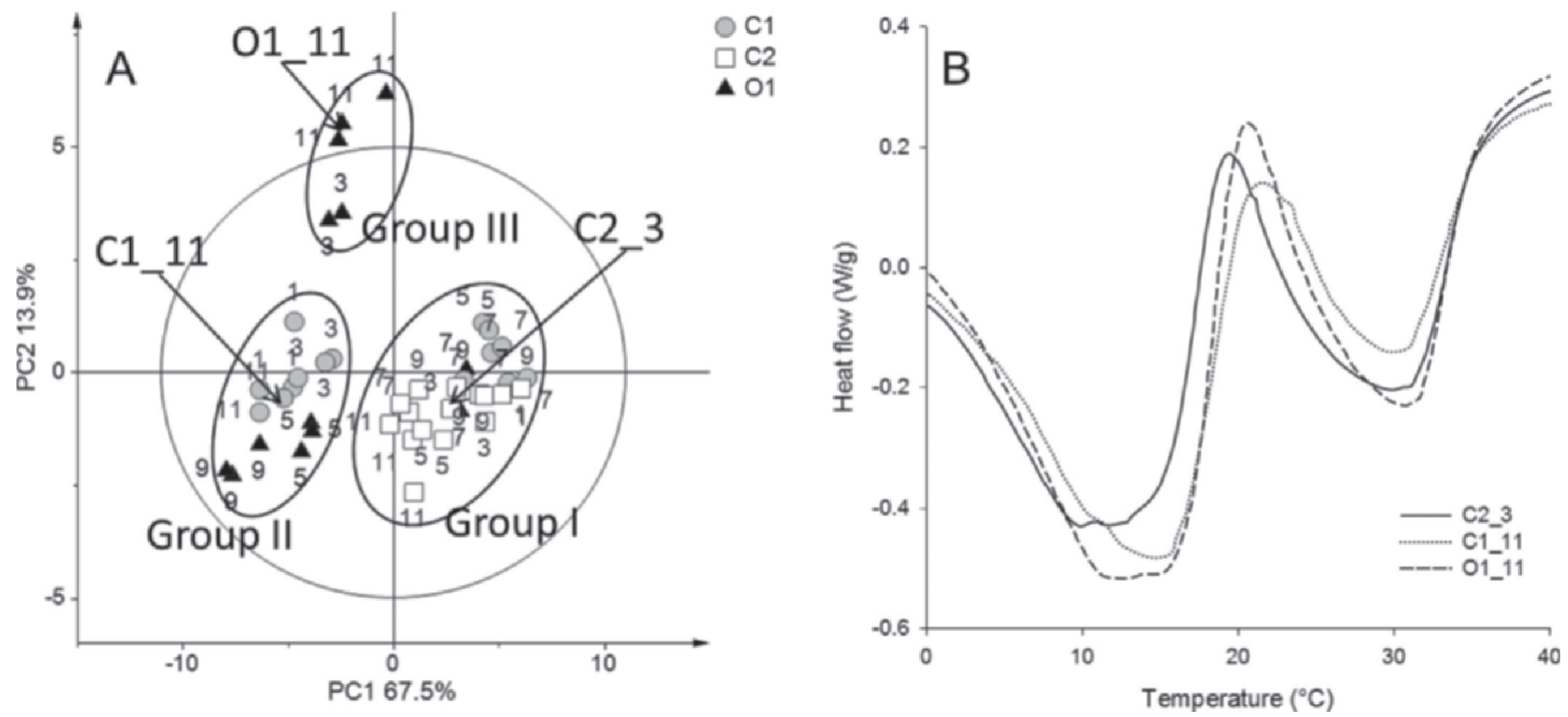

Figure 5. Principal component (PC) analysis of differential scanning calorimetry (DSC) thermograms of milk fat samples from 2 conventional (C1 and C2) and 1 organic (O1) dairy. (A) Plot of scores labeled by period of sampling $(1=$ January-February; $3=$ March-April; $5=$ May-June; 7 = July-August; 9 = September-October; 11 = November-December). (B) DSC thermograms of representative samples of the 3 groups (I, II, and III) obtained in A.

tion was known. A PLS analysis where FA were used as $\mathrm{X}$ variables and melting points as $\mathrm{Y}$ variables revealed a model where 66,14 , and $5 \%$ of the variation in $\mathrm{LMF}$, MMF, and HMF, respectively, melting points could be explained. For the LMF melting point, $61 \%$ could be predicted based on cross validation, and coefficients of the individual FA are shown in Figure 6. The main FA contributing positively to the LMF melting point were C16:0 and C14:0, whereas the main FA contributing negatively to the LMF melting point were C18:1 cis-9 and C18:0.

The influence of $\mathrm{C} 16: 0$ and $\mathrm{C} 18: 1$ cis-9 $\mathrm{FA}$ on the melting point is in agreement with data recently reported from our research group (Buldo et al., 2013); however, in that study, no effects of C14:0 and C18:0 were found, and a negative influence of $\mathrm{C} 14: 1$ and CLA cis-9,trans-11 on the melting point was reported. The difference between the present results and those obtained by Buldo et al. (2013) can be attributed to different methods, as Buldo et al. (2013) studied cream that had been cooled to $4^{\circ} \mathrm{C}$ before the melting process; in contrast, we used $-40^{\circ} \mathrm{C}$ and anhydrous milk fat in the present study. This difference in procedures will likely affect changes in the melting point and composition of LMF. However, it should be noted that the main difference between their study and our results is the influence of C14:1 and CLA cis-9,trans-11. Both these FA are formed by mammary desaturase activity, which is affected by genetics (Poulsen et al., 2012), and the results reported by Buldo et al. (2013) are based on individual cow samples, whereas the samples used for DSC in the present study were pooled samples of dairy bulk milk. Thus, the individual differences between animals may have influenced the results to a large ex-

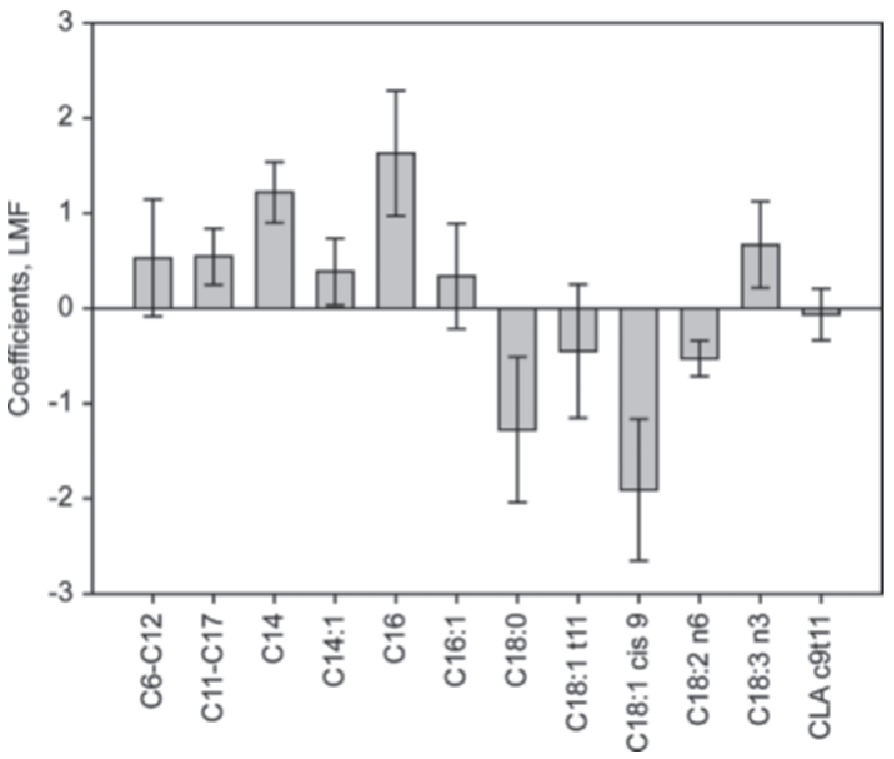

Figure 6. Partial least squares projection to latent structure analysis for prediction of melting point of the low melting fraction (LMF) from FA composition. Coefficients of the individual FA. $\mathrm{t}=$ trans; $\mathrm{c}$ $=$ cis. 
tent in the study of Buldo et al. (2013), whereas this difference was practically nonexistent in our study. The relations demonstrate how the melting point increased when milk fat contained higher amounts of C14 and C16:0 and decreased when the content of C18:1 cis9 increased. This is in accordance with lower melting points of unsaturated FA compared with SFA. However, C18:0 contributed to a decrease in melting point, which cannot be explained by the properties of this $\mathrm{FA}$, and the relation is mainly due to the fact that C18:0 and C18:1 cis-9 are closely related, as C18:0 is the substrate for formation of $\mathrm{C} 18: 1$ cis- 9 by mammary desaturase activity. The melting points of the MMF and the HMF could not be modeled by the FA composition, which could be ascribed to the lower variation in these parameters. This was also seen by the lack of difference between dairies. Moreover, it may be difficult to affect this fraction by altering the feed consumed by the dairy cow, as the milk fat is kept fluid at cow body temperature as a function of the desaturase system.

Studies where the proportion of unsaturated FA in milk fat has been increased by feeding have shown effects on the crystallization and melting behavior of isolated anhydrous milk fat (Couvreur et al., 2006; OrtizGonzalez et al., 2007; Smet et al., 2010). A high content of unsaturated FA decreases melting temperatures and decreases the solid fat content, especially below $20^{\circ} \mathrm{C}$, due to an increased proportion of low-melting triglycerides (Smet et al., 2010).

In the study by Couvreur et al. (2006), cows were fed different proportions of fresh grass and variation in FA composition of milk fat was similar to the variation in the present study. Minor differences in crystallization and melting temperatures are observed, whereas the solid fat content at different temperatures is affected to a larger extent. Those authors concluded that the ratio between $\mathrm{C} 16: 0$ and $\mathrm{C} 18: 1$ affects the thermal properties, and they report C16:0 and C18:1 as the spreadability index, although the spreadability measured by sensory analysis was not affected by treatments. However, the melting and firmness in mouth mirror the lesser solid fat content at high grass proportions (Couvreur et al., 2006).

Ortiz-Gonzalez et al. (2007) have investigated how melting behavior of milk fat is affected after abomasal infusion of vegetable oils. They found a positive correlation between melting point, as well as solid fat content and the content of C16:0 in milk fat, which is in accordance with our results. However, they also find the strongest negative correlation between the content of C18:2 in milk fat and melting point, as well as solid fat content, and no significant correlations between C18:1 cis-9 and melting points and solid fat content. Due to the abomasal infusion, they obtained C18:2 concentra- tions in milk fat ranging from 2.4 to $14.5 \mathrm{~g} / 100 \mathrm{~g}$; such high concentrations cannot be obtained through feeding, as the major part of C18:2 would be hydrogenated in the rumen.

\section{CONCLUSIONS}

The current study has shown that milk FA and TAG composition varies between dairies, and the largest differences were observed between dairy $\mathrm{O} 1$ and $\mathrm{C} 2$. A seasonal variation in the FA composition was observed, and this variation was most pronounced for organic milk. The DSC analysis of the melting behavior showed that milk fat samples could be separated into 3 groups, and this grouping could not be directly related to FA or TAG composition. Melting point of the LMF was higher for organic milk fat than for conventional milk, and this melting point could be related to the FA composition of milk fat, especially the content of $\mathrm{C} 16: 0$ and $\mathrm{C} 18: 1$ cis-9. Melting points of the MMF and the HMF showed no significant differences between dairies and could not be related to FA composition. It was not possible to relate melting points to TAG composition because classes of TAG rather than individual TAG were determined. Recent developments in the calibration of infrared instruments for monitoring milk composition have given the possibility to predict the content of major FA; therefore, it would be possible to determine values for content of $\mathrm{C} 16: 0$ and $\mathrm{C} 18: 1$ cis-9 in milk fat at the line. This information would make it possible to maintain a uniform texture of butter, as the temperature treatment of each batch of cream could be optimized based on the knowledge of the FA composition.

\section{ACKNOWLEDGMENTS}

The authors thank the Danish Dairy Research Foundation (Aarhus, Denmark) and the Danish Ministry of Food, Agriculture and Fisheries (Copenhagen, Denmark) for financing this study. The dairies Arla Foods (Taulov and Rødkjærsbro, Denmark) and Thise Dairy (Roselv, Denmark) are gratefully acknowledged for supply of milk and knowledge.

\section{REFERENCES}

Buldo, P., M. K. Larsen, and L. Wiking. 2013. Multivariate data analysis for finding the relevant fatty acids contributing to the melting fractions of cream. J. Sci. Food Agric. 93:1620-1625.

Butler, G., J. H. Nielsen, M. K. Larsen, B. Rehberger, S. Stergiadis, A. Canever, and C. Leifert. 2011. The effects of dairy management and processing on quality characteristics of milk and dairy products. NJAS Wagening. J. Life Sci. 58:97-102. http://dx.doi. org/10.1016/j.njas.2011.04.002.

Butler, G., J. H. Nielsen, T. Slots, C. Seal, M. D. Eyre, R. Sanderson, and C. Leifert. 2008. Fatty acid and fat-soluble antioxidant concentrations in milk from high- and low-input conventional and organic systems: Seasonal variation. J. Sci. Food Agric. 88:1431-1441. 
Chen, S., G. Bobe, S. Zimmerman, E. G. Hammond, C. M. Luhman T. D. Boylston, A. E. Freeman, and D. C. Beitz. 2004. Physical and sensory properties of dairy products from cows with various milk fatty acid compositions. J. Agric. Food Chem. 52:3422-3428.

Couvreur, S., C. Hurtaud, C. Lopez, L. Delaby, and J. L. Peyraud. 2006. The linear relationship between the proportion of fresh grass in the cow diet, milk fatty acid composition, and butter properties. J. Dairy Sci. 89:1956-1969.

European Council. 2007. Council Regulation (EC) No 834/2007 of 28 June 2007 on organic production and labelling of organic products and repealing Regulation (EEC) No 2092/91. Accessed Nov. 21. 2013. http://eur-lex.europa.eu/LexUriServ/LexUriServ.do?uri= OJ:L:2007:189:0001:0023:EN:PDF.

Foedevarestyrelsen. 2011.Instruksforvelfærdskontrolikvægbesætninger. Accessed Nov. 21. 2013. http://www.foedevarestyrelsen.dk/Sites CollectionDocuments/25_PDF_word_filer\%20til\%20download/ 05kontor/Dyrevelf\%C3\%A6rd\%20Instrukser\%20Tjeklister\%20 2012/Instruks\%20kv\%C3\%A6g\%20okt\%202011.pdf.

Heck, J. M. L., H. J. F. van Valenberg, J. Dijkstra, and A. C. M. van Hooijdonk. 2009. Seasonal variation in the Dutch bovine raw milk composition. J. Dairy Sci. 92:4745-4755.

Hurtaud, C., F. Faucon, S. Couvreur, and J. L. Peyraud. 2010. Linear relationship between increasing amounts of extruded linseed in dairy cow diet and milk fatty acid composition and butter properties. J. Dairy Sci. 93:1429-1443.

ISO (International Organization for Standardization). 2010. ISO 17678: Milk and milk products-Determination of milk fat purity by gas chromatographic analysis of triglycerides. ISO, Geneva, Switzerland.
Jensen, R. G. 2002. The composition of bovine milk lipids: January 1995 to December 2000. J. Dairy Sci. 85:295-350.

Larsen, M. K., U. Kidmose, T. Kristensen, P. Beaumont, and G. Mortensen. 2013. Chemical composition and sensory quality of bovine milk as affected by type of forage and proportion of concentrate in the feed ration. J. Sci. Food Agric. 93:93-99.

Larsen, M. K., J. H. Nielsen, G. Butler, C. Leifert, T. Slots, G. H Kristiansen, and A. H. Gustafsson. 2010. Milk quality as affected by feeding regimens in a country with climatic variation. J. Dairy Sci. 93:2863-2873.

Ortiz-Gonzalez, G., R. Jimenez-Flores, D. R. Bremmer, J. H. Clark, E. J. DePeters, S. J. Schmidt, and J. K. Drackley. 2007. Functional properties of butter oil made from bovine milk with experimentally altered fat composition. J. Dairy Sci. 90:5018-5031.

Poulsen, N. A., F. Gustavsson, M. Glantz, M. Paulsson, L. B. Larsen, and M. K. Larsen. 2012. The influence of feed and herd on fatty acid composition in 3 dairy breeds (Danish Holstein, Danish Jersey, and Swedish Red). J. Dairy Sci. 95:6362-6371.

Shi, Y., C. M. Smith, and R. W. Hartel. 2001. Compositional effects on milk fat crystallization. J. Dairy Sci. 84:2392-2401.

Smet, K., K. Coudijzer, E. Fredrick, S. De Campeneere, J. De Block, J. Wouters, K. Raes, and K. Dewettinck. 2010. Crystallization behavior of milk fat obtained from linseed-fed cows. J. Dairy Sci 93:495-505.

Toledo, P., A. Andren, and L. Bjorck. 2002. Composition of raw milk from sustainable production systems. Int. Dairy J. 12:75-80. 